\title{
What intrinsic and extrinsic factors explain the stoichiometric diversity of aquatic heterotrophic bacteria?
}

\author{
Casey M Godwin and James B Cotner \\ Department of Ecology, Evolution, and Behavior, University of Minnesota, Saint Paul, MN, USA
}

\begin{abstract}
The elemental content of microbial communities is dependent upon the physiology of constituent populations, yet ecological stoichiometry has made slow progress toward identifying predictors of how species and strains change the elemental content of their biomass in response to the stoichiometry of elements in resources. We asked whether the elemental content of aquatic bacteria, especially flexibility in elemental content, could be predicted by their phylogeny, maximum growth rate or lake productivity. We examined 137 isolates using chemostats and found that strains differed substantially in how the carbon:nitrogen:phosphorus ratios (C:N:P) in their biomass responded to P-sufficient and P-limiting conditions. The median strain increased its biomass C:N:P from 68:14:1 to 164:25:1 under P limitation. Patterns in elemental content and ratios were partly explained by phylogeny, yet flexibility in elemental content showed no phylogenetic signal. The growth rate hypothesis predicts that $\mathbf{P}$ content is positively related to growth rate, but we found weak correlation between maximum growth rate and $P$ content among the strains. Overall, isolates from highly productive lakes had higher maximum growth rates and less flexible biomass $N: P$ than isolates from unproductive lakes. These results show that bacteria present within lake communities exhibit diverse strategies for responding to elemental imbalance.
\end{abstract}

The ISME Journal (2018) 12, 598-609; doi:10.1038/ismej.2017.195; published online 24 November 2017

\section{Introduction}

Bacteria are key factors in the Earth's biogeochemical cycles, and although they typically comprise a fraction of the total biomass in ecosystems, they have a disproportionate influence on the fluxes of elements. Bacterial biomass and metabolism couple multiple element cycles, and the strength of this coupling depends upon the stoichiometry of elements, such as carbon (C), nitrogen $(\mathrm{N})$ and phosphorus (P), in bacterial biomass. Models of biogeochemical processes often assume that the stoichiometry of these elements in microbial biomass resembles that of marine plankton, referred to as the Redfield ratio (106C:16N:1P, (Redfield, 1958). However, the ratio of $\mathrm{C}, \mathrm{N}$ and $\mathrm{P}$ in biomass of heterotrophic and autotrophic bacteria (that is, their biomass stoichiometry) is highly flexible (Goldman et al., 1987; Godwin and Cotner, 2015a; Martiny

Correspondence: CM Godwin, Department of Ecology, Evolution, and Behavior, University of Minnesota, 1987 Upper Buford Circle, Saint Paul, Minnesota 55108 USA.

Current address: School of Natural Resources and Environment, University of Michigan, 440 Church Street, Ann Arbor, Saint Paul, MI 48108, USA.

E-mail: godwi018@umn.edu

Received 26 April 2017; revised 7 September 2017; accepted 9 October 2017; published online 24 November 2017 et al., 2016). This flexibility is the result of changes in the amount of $\mathrm{C}, \mathrm{N}$ and $\mathrm{P}$ in each cell (elemental quotas), which depends upon factors such as cell size (Garcia et al., 2016), growth rate (Godwin et al., 2017) and accumulation of surplus $C$ and $P$ in storage molecules or vacuoles (Davelaar, 1993; Thingstad et al., 2005). This flexibility impacts biogeochemical fluxes at the global scale (Galbraith and Martiny, 2015), but as detailed information on stoichiometry is available for only a few, if any, of the species within microbial communities, there is a need to identify patterns that allow for generalization.

Here we seek to characterize how biomass elemental composition varies among strains of aquatic heterotrophic bacteria, and to determine whether key patterns from ecological stoichiometry can be applied to help understand these interspecific differences. We focus specifically on stoichiometric flexibility, which is the capacity of an organism to alter the stoichiometry of its biomass in response to changes in the stoichiometry of elements as resources. Most of the interspecific comparisons of biomass stoichiometry have been performed using a single level of resource stoichiometry, which can help identify broad patterns in stoichiometry (Nielsen et al., 1996; Quigg et al., 2003; Hillebrand et al., 2013), but cannot assess differences in stoichiometric flexibility among taxa. For example, 
phytoplankton are often assumed to be the exemplar group for understanding stoichiometric flexibility, yet a recent data synthesis found only 20 data sets that could be used to quantify stoichiometric flexibility in algae (Persson et al., 2010) and many models are based upon a single empirical data set (Rhee, 1978). There was a similar lack of empirical data on stoichiometric flexibility in bacteria (Makino et al., 2003), but recent studies have used a common method to compare among multiple strains and found substantial variation in stoichiometric flexibility (Scott et al., 2012; Godwin and Cotner, 2015b). Presently, we lack an understanding of what leads to variation in stoichiometric flexibility among heterotrophic bacteria, so we sought to identify ecophysiological, biogeographic and phylogenetic correlates of flexibility using a survey of diverse isolates from freshwater lakes.

The growth rate hypothesis (GRH; Elser et al., $2000,2003)$ predicts that the $\mathrm{P}$ content of cells is proportional to their growth rate, because of the demand for P-rich ribosomal RNA required for rapid growth rates. The GRH is one case of a more general principle that a cell's elemental quota is positively related to its growth rate (Droop, 1973; Rhee, 1973). Much of the support for the GRH comes from studies investigating the effect of relative growth rate within one species (that is, growth rate as a fraction of the maximum growth rate $\mu_{\max }$ ). While studies using both autotrophic (Garcia et al., 2016) and heterotrophic (Makino et al., 2003) bacteria support the GRH, an important question is whether $\mu_{\max }$ is an important predictor of interspecific variation in elemental content and stoichiometry. Within and among phytoplankton species, $\mathrm{N}$ and $\mathrm{P}$ content generally increase with growth rate (Nielsen et al., 1996), but the relationship between growth rate and $\mathrm{P}$ content is weak among strains of heterotrophic bacteria (Mouginot et al., 2014; Zimmerman et al., 2014; Godwin and Cotner, 2015b). In addition, although we know that phytoplankton, cyanobacteria and heterotrophic bacteria exhibit less stoichiometric flexibility when growing near their $\mu_{\max }$ (Goldman et al., 1979; Garcia et al., 2016; Godwin et al., 2017), it is unclear whether strains with higher $\mu_{\max }$ have more or less potential for stoichiometric flexibility. Here we tested the utility of the GRH for comparing multiple strains of heterotrophic bacteria, using uniform experimental conditions to help isolate differences among strains from the wellknown effects of growth rate within each strain.

Another potential influence on the stoichiometric flexibility of bacterial isolates is their source environment and the particular conditions used for isolation and cultivation. Previous work has shown that enrichment assemblages of bacteria from lakes are stoichiometrically flexible (Makino and Cotner, 2004; Godwin and Cotner, 2015a) and that P limitation selects for flexible members of the assemblage, whereas C limitation can select for more homeostatic assemblages (Godwin and Cotner,
2014). Another study found that isolates from an oligotrophic lake had lower P quotas and were more flexible than those from a more productive lake (Godwin and Cotner, 2015b). Despite these findings, it remains unclear whether stoichiometric flexibility of bacterial isolates is consistently different between oligotrophic and highly productive lakes. We hypothesized that strains isolated from oligotrophic lakes would have more flexible stoichiometry and lower $\mu_{\max }$ than isolates from eutrophic lakes.

If key parameters such as $\mu_{\max }$, minimum elemental content or stoichiometric flexibility are similar for closely related taxa, their phylogenetic affiliation could be used to infer the physiology of taxa without the need for experimentation. Previous studies have shown that biomass stoichiometry is partly explained by phylogenetic affiliation in fish (Hendrixson et al., 2007), soil microbes (Mouginot et al., 2014) and tree leaves (Sardans et al., 2011). But other studies have reported no significant phylogenetic signal for biomass stoichiometry in freshwater phytoplankton (Narwani et al., 2015) and marine heterotrophic bacteria (Zimmerman et al., 2014). Owing to a lack of data on the stoichiometric flexibility of different bacterial taxa, it remains unclear whether phylogenetic affiliation could be used to reliably infer patterns in stoichiometric flexibility in communities. We performed an experiment to determine whether phylogenetic affiliation, $\mu_{\max }$ or lake trophic state could be used to predict the biomass stoichiometry, stoichiometric flexibility in response to P limitation, and cell quotas of heterotrophic bacteria from lakes.

\section{Materials and methods}

Bacterial isolation and cultivation

We sampled four oligotrophic lakes and five eutrophic lakes in Minnesota and Iowa, USA (Supplementary Table 1). These natural lakes had a maximum depth of at least $5 \mathrm{~m}$ and were sampled from the upper mixed layer between June and August. We filtered the water samples through sterile Whatman GF/A filters (nominal $1.6 \mu \mathrm{m}$ retention) under low pressure to exclude larger plankton. We immediately inoculated this bacteria-sized fraction onto either solid media (direct plating method) or into liquid medium (dilution to extinction method (Godwin and Cotner, 2015b). Basal microbiological medium was prepared following Tanner (2002) as described previously (Godwin and Cotner, 2015b). Whereas direct plating can lead to overrepresentation of strains that form large and conspicuous colonies, the dilution to extinction method can provide a more representative sample of the cultivatable strains in the sample. $\mathrm{C}$ was supplied as either glucose or acetate at $23.88 \mathrm{mmol}-\mathrm{C}^{-1}$ and $\mathrm{P}$ was supplied as potassium phosphate at concentrations of $238.8 \mu \mathrm{mol}-\mathrm{P} \mathrm{l}^{-1}$ (P sufficient, C: $\mathrm{P}_{\text {supply }}$ of 100:1) or $0.239 \mu \mathrm{mol}-\mathrm{P} \quad \mathrm{l}^{-1}$ (P limiting, C:P of 
100 000:1). Previous work has shown that these two levels of C:P $P_{\text {supply }}$ can efficiently diagnose the range of stoichiometric flexibility in bacterial isolates, and that the C:P $\mathrm{P}_{\text {supply }}$ level of 100:1 represents C limitation (Scott et al., 2012; Godwin and Cotner, 2014).

We performed dilution to extinction isolation using basal microbiological medium with either glucose or acetate as the C source and C:P of 100:1 or 100 000:1. The dilution method was previously described in detail (Scott et al., 2012; Godwin and Cotner, 2015b). Briefly, the bacteria-sized fraction of lake water was diluted into medium containing resazurin, viable bacteria respired the resazurin to fluorescent resofurin, and the fluorescence of resofurin was used to determine viability at each dilution. For each medium formulation and lake, we used 15 replicate dilution series, with 6 dilutions from 0.15 to $1 \times 10^{-5}$ and 6 control wells without inoculum. After 13-29 days of incubation in the dark at $22-24^{\circ} \mathrm{C}$, no new positive wells appeared and we randomly selected six positive wells from the highest dilutions. We harvested an aliquot from these wells and plated it onto solid medium with the same formulation, then followed the steps for the direct plating method. We also plated samples of the bacteria-sized fraction onto solid agar medium with acetate or glucose as C sources and C:P of 100:1 or 100 000:1 in a complete factorial design. We incubated the agar plates at $22-24^{\circ} \mathrm{C}$ and characterized putative isolates based upon distinct colony morphology within each combination of lake and medium. One colony of each putative type was re-streaked twice onto fresh medium to obtain an axenic culture. Isolate cultures were mixed with $15 \%$ glycerol and stored at $-80^{\circ} \mathrm{C}$ until use.

\section{Isolates selection and characterization}

From each lake, we screened up to five randomly selected strains from each medium formulation used for the dilution method and from direct plating. Isolates that showed reliable growth after cryo-storage were used for the experiments (Supplementary Table S2). We extracted and purified DNA using the GeneJET spin kits (Thermo Fisher, Waltham, MA, USA) and amplified partial 16S ribosomal DNA sequences by PCR using primer pairs $8 \mathrm{~F}$ and $1522 \mathrm{R}$ or $338 \mathrm{~F}$ and 907R (Ghosh and LaPara, 2007). The products were cleaned using the GeneClean II kit (MP Biomedicals, Solon, OH, USA) and sequenced on an Applied Biosystems 3730xl Sanger sequencer. Base calling was performed using Codon Code Aligner software with the Phrap algorithm. We classified the strains using the Ribosomal Database Project classifier version 2.10 and obtained aligned $16 \mathrm{~S}$ sequences from the nearest match to a type strain isolate. These sequences were used to prepare the phylogeny using a maximum likelihood nearestneighbor method in Mega version 7 (Tamura et al., 2013). Confidence for each branch of the phylogeny was determined through 500 bootstrap iterations.
Chemostat cultures

For each isolate, we measured $\mu_{\max }$ in medium with the same $\mathrm{C}$ source that was used for isolation (either glucose or acetate) and a C:P of 100:1. Batch cultures were maintained at $22-24{ }^{\circ} \mathrm{C}$ on an orbital shaker. At least five consecutive measurements of optical density at $600 \mathrm{~nm}\left(0.005-0.100 \mathrm{~cm}^{-1}\right)$ were used to estimate $\mu_{\max }$ of each strain. The isolates were inoculated into chemostats that were diluted at $30-40 \%$ of $\mu_{\max }$ using peristaltic pumps (Godwin and Cotner, 2014). The chemostats were supplied with medium of the same $C$ source as used for isolation. The concentration of inorganic $\mathrm{P}$ in the medium was either $239 \mu$ mol-P $\mathrm{l}^{-1}$ (P replete, C: $\mathrm{P}_{\text {supply }}$ of 100:1) or $2.39 \mu \mathrm{mol}-\mathrm{P} \mathrm{l}^{-1}$ (P limiting, C:P of $10000: 1)$. The chemostats were mixed with sterile filtered air and maintained in the dark at $20^{\circ} \mathrm{C}$. The cultures were harvested after nine complete turnovers of the reactor volume.

Samples for biomass C, N and P were collected onto combusted glass fiber filters $(\mathrm{GF} / \mathrm{F}$ grade, Whatman, Little Chalfont, UK). Biomass C and N was determined using a carbon-hydrogen-nitrogen analyzer. $\mathrm{P}$ content of the filters was determined by acid persulfate digestion, followed by the molybdenum blue method (American Public Health Association, 1995) using NIST spinach leaf as a recovery standard for $\mathrm{P}$. We measured soluble reactive $\mathrm{P}$ in filtrate from the chemostats run at $\mathrm{C}$ : $\mathrm{P}_{\text {supply }}$ of $10000: 1$ (American Public Health Association, 1995). We measured residual glucose at $\mathrm{C}: \mathrm{P}_{\text {supply }}$ of $100: 1$ for a subset of the strains $(n=25)$ using the glucose oxidase method (Thermo Fisher, A22189). On average, the subset of strains depleted glucose by $94.6 \%$ and several strains depleted glucose below $10 \mathrm{umoll}^{-1}$. To quantify bacterial abundance and relative size, samples from each culture were fixed with formalin, then diluted with sodium pyrophosphate and vortexed to improve cell dispersion (Velji and Albright, 1993). Despite this pre-treatment, some cultures formed clumps of cells and therefore we have no abundance data. Samples were stained with SybrGreen (Invitrogen, Waltham, MA, USA) to a final dilution of $2000 \times$ and incubated for at least $10 \mathrm{~min}$ before measurement (Lebaron et al., 2001). Standardized fluorescent beads were added to each sample as an internal standard to enumerate cells. Cytometry was performed using a FACSCalibur (Becton Dickinson, Franklin Lakes, NJ, USA) with a $488 \mathrm{~nm}$ laser. Side scatter and fluorescence at $530 \mathrm{~nm}$ were used to identify populations of cells and beads. At least 9000 cell events were recorded for each sample.

\section{Statistical analyses}

We included data from 21 strains of bacteria that were previously characterized using the same methods (Godwin and Cotner, 2015b). We computed molar ratios of $\mathrm{C}, \mathrm{N}$ and $\mathrm{P}$ in biomass and calculated element quotas by dividing the concentrations of 

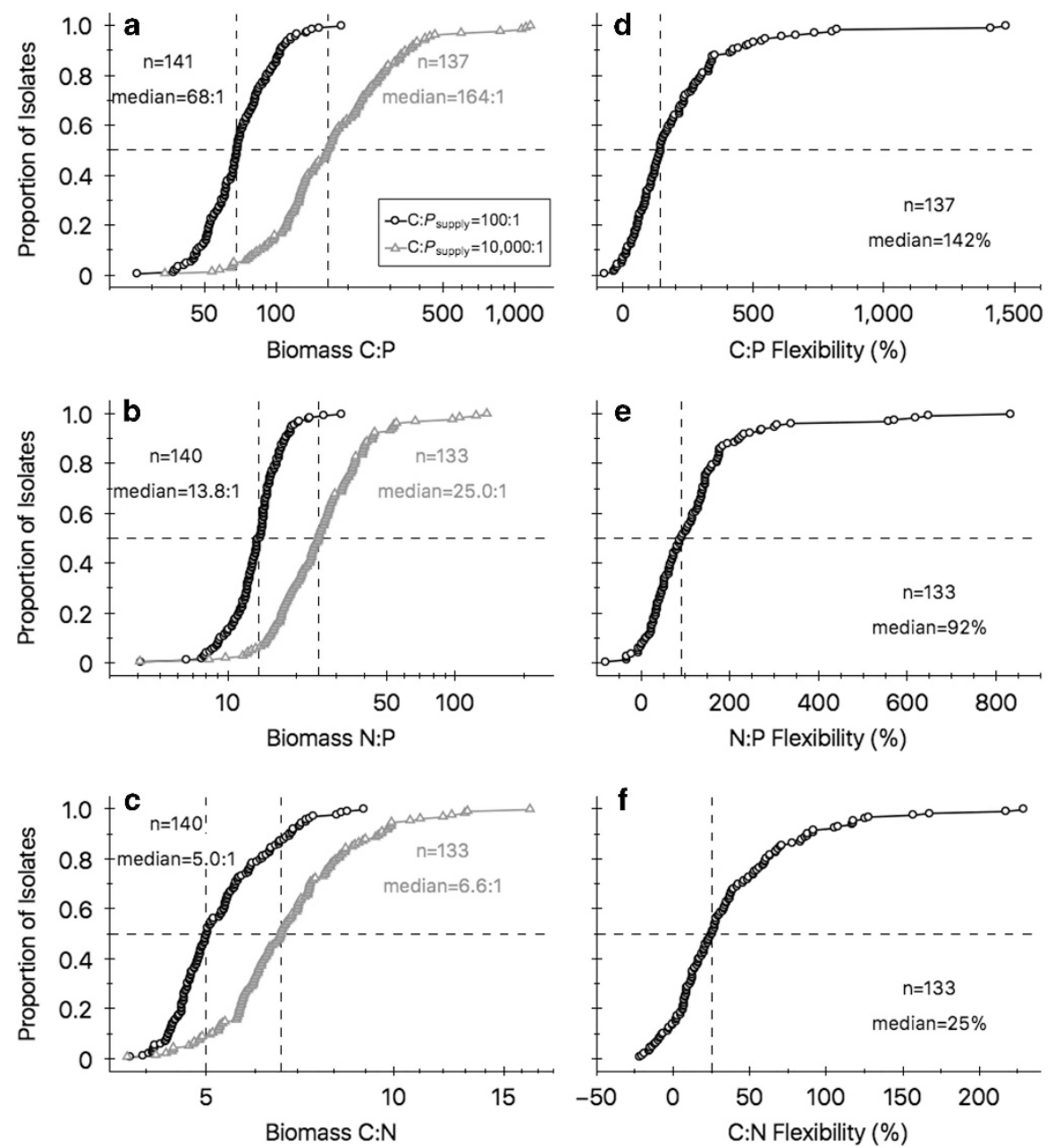

Figure 1 (a-c) Cumulative distribution functions for biomass stoichiometry under P sufficiency (black) and P limitation (gray). For any value of biomass stoichiometry (horizontal axes), the vertical axes display the cumulative proportion of isolates exhibiting an equal or lesser value. Each data point represents the value from an individual strain and dashed gridlines denote the median value for each data set. (d-f) Cumulative distribution functions for the relative change in biomass stoichiometry between C:P $\mathrm{P}_{\text {supply }}$ of 100:1 and 10 000:1. Positive values indicate that the stoichiometry increased under P limitation.

particulate $\mathrm{C}, \mathrm{N}$ or $\mathrm{P}$ by the cell abundance. Biomass stoichiometry and cell quotas were log-transformed before statistical analyses in order to meet the assumptions of approximate normality and homogeneity of variances. Stoichiometric flexibility was quantified as the percent increase (positive) or decrease (negative) in biomass element ratio between $\mathrm{C}: \mathrm{P}_{\text {supply }}$ of 100:1 and $10000: 1$. Flexibility is known to change with growth rates (Makino et al., 2003; Godwin et al., 2017), temperature (Phillips et al., 2017) and C:P $\mathrm{P}_{\text {supply }}$ (Godwin and Cotner, 2015b), so we treat this measurement of flexibility not as an intrinsic property of the strains but as a metric for comparing the response of strains to $\mathrm{P}$ availability under similar conditions.

We used two related tests for phylogenetic signal: K (Blomberg et al., 2003; Münkemüller et al., 2012) and lambda (Pagel, 1999). Both of these methods are designed to test whether closely related taxa have more similar trait values, where the null expectation is that the observed trait values are the result of random evolution along the hypothesized phylogeny. Values of lambda or $\mathrm{K}$ close to zero indicate low phylogenetic signal, whereas values close to 1 indicate strong phylogenetic signal. Lambda ranges from 0 to 1 , but $\mathrm{K}$ can be $>1$. As both methods are dependent upon the hypothesized tree (Münkemüller et al., 2012), we used these tools to compare the strength of phylogenetic signal in different traits and comparisons with results from the literature are for illustrative purposes only. We used the function 'phylosig' in the R package 'phytools' to test the phylogenetic signal in each parameter (Revell, 2012). We performed linear regressions of stoichiometric ratios and elemental quotas versus $\mu_{\max }$ using the function 'pgls' in the R package 'caper' (Freckleton et al., 2002). To test for allometric scaling of elemental quotas, we performed standardized major axis regressions and tested for isometric scaling using the R package 'smatr' (Warton et al., 2006). We also performed phylogenetic reduced major axis regression using the R package 'phytools' (Revell, 2012). For the strains isolated as part of the present study, we evaluated the effect of lake trophic 
state (oligotrophic or eutrophic), C source (glucose or acetate) and isolation medium C:P on distribution (Kolmogorov-Smirnov test) and median value (Mann-Whitney test) of each parameter. These comparisons were accompanied by phylogenetic analysis of variance (ANOVA) tests using the function 'phylANOVA' in 'phytools' (Garland et al., 1993; Revell, 2012).

\section{Results}

Figure 1 shows that the isolates exhibited substantial variability in both their biomass stoichiometry and stoichiometric flexibility. For all three stoichiometric ratios, there was a large shift toward higher ratios at $\mathrm{C}: \mathrm{P}_{\text {supply }}$ of $10000: 1$. Stoichiometric flexibility was greatest for $\mathrm{C}: \mathrm{P}_{\text {biomass }}$ (median of $142 \%$ increase under $\mathrm{P}$ limitation), followed by $\mathrm{N}: \mathrm{P}_{\text {biomass }}$ (median of $92 \%$ increase) and $\mathrm{C}: \mathrm{N}_{\text {biomass }}$ (median of $25 \%$ increase).

Figure 2 shows that certain phylogenetic groups had higher $\mu_{\max }$, namely the phyla gammaproteobacteria and bacteroidetes. The $\mu_{\max }$ of isolates obtained in this study ranged from 0.019 to $0.676 \mathrm{~h}^{-1}$ (median $0.158 \mathrm{~h}^{-1}$ ), which corresponds to doubling times between 1 and $36 \mathrm{~h}$. The phylogenetic signal for $\mu_{\max }$ was stronger than for the other traits measured (Table 1). Biomass stoichiometric ratios showed moderate phylogenetic signal at $\mathrm{C}: \mathrm{P}_{\text {supply }}$ of 100:1, indicating that related species differed more than expected based on their phylogeny, but much less phylogenetic signal at $\mathrm{C}: \mathrm{P}_{\text {supply }}$ of 10 000:1. The phylogenetic signal in stoichiometric flexibility was very low (lambda $<0.001$ ), although a few clades were populated with mostly flexible strains (Figure 2). Fewer complete records were available for elemental quotas (Supplementary Figure S1), but those data showed similar patterns to biomass stoichiometry. At $\mathrm{C}: \mathrm{P}_{\text {supply }}$ of $10000: 1$, the strains depleted the soluble reactive $\mathrm{P}$ to a median concentration of $0.112 \mu \mathrm{mol}-\mathrm{P}^{-1}$ (from an initial concentration of $2.39 \mu_{m o l ~} \mathrm{l}^{-1}$ ), but this concentration showed no phylogenetic signal.

Figures 3a-f show that there was a significant relationship between biomass stoichiometry of the isolates and their growth rate, when all strains were grown at $0.3-0.4$ of their $\mu_{\max }$. At $\mathrm{C}: \mathrm{P}_{\text {supply }}$ of $100: 1$, all three stoichiometric ratios decreased significantly with growth rate, but this correlation was stronger for $\mathrm{C}: \mathrm{P}_{\text {biomass }}$ and $\mathrm{N}: \mathrm{P}_{\text {biomass }}$ than $\mathrm{C}: \mathrm{N}_{\text {biomass }}$ (Supplementary Table S3). At C:P $\mathrm{P}_{\text {supply }}$ of $10000: 1$, only $\mathrm{C}: \mathrm{P}_{\text {biomass }}$ and $\mathrm{N}: \mathrm{P}_{\text {biomass }}$ showed significant decreases with growth rates, and although the slopes were more negative than at $\mathrm{C}: \mathrm{P}_{\text {supply }}$ of 100:1, the low $r^{2}$ values (0.08 and 0.085 , respectively) indicated that

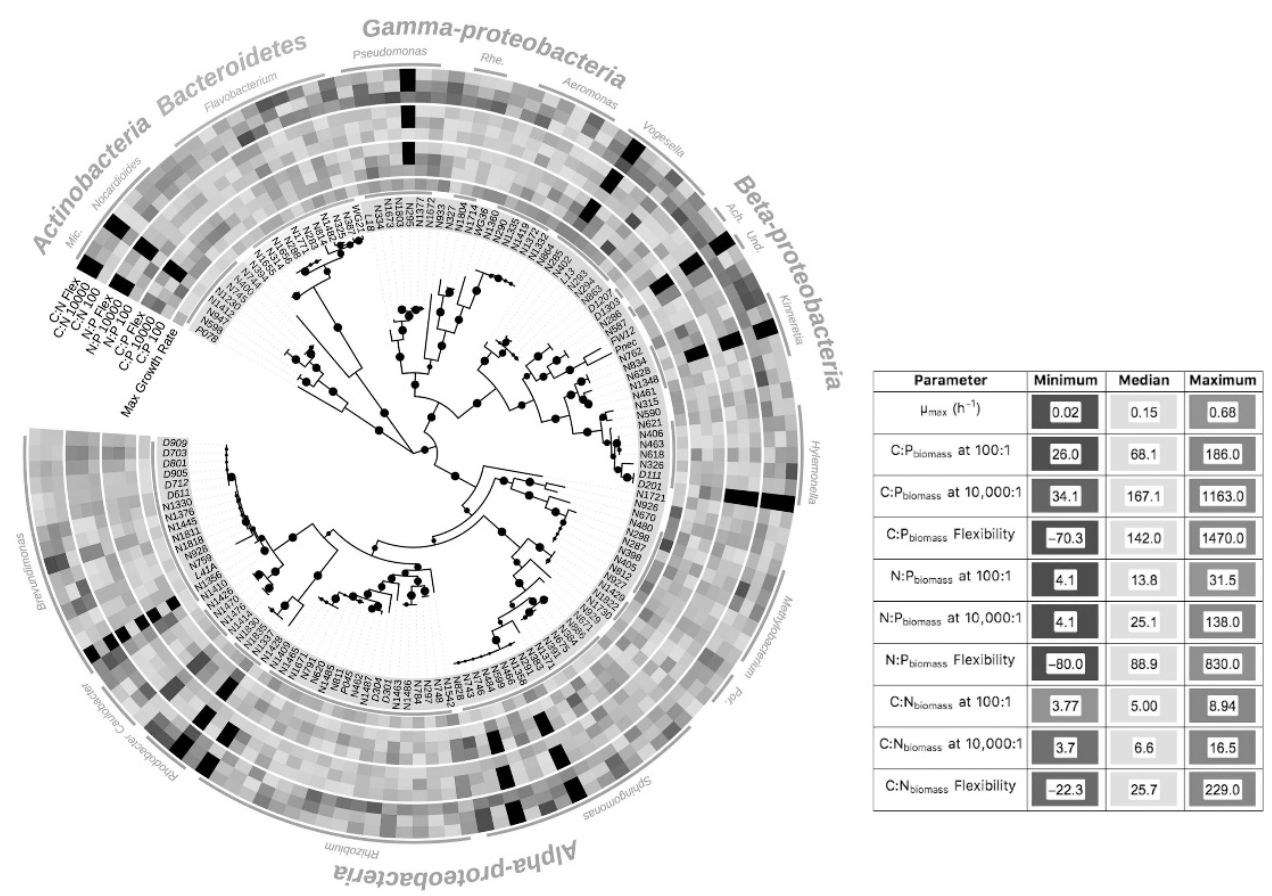

Figure 2 Phylogeny of the isolates with heatmap showing $\mu_{\max }$ and biomass C:P, N:P and C:N stoichiometry. For each elemental ratio, the heatmap displays the scaled values at C: $\mathrm{P}_{\text {supply }}$ of 100:1, C:P $\mathrm{P}_{\text {supply }}$ of 10 000:1, and flexibility in the ratio. The heatmap values were scaled separately for each parameter by normalizing the log-transformed values to a median of 0 . The minimum (blue), median (gray) and maximum values (red) for each parameter correspond to the values in Figure 1. Black coloring indicates missing data. Bootstrapped confidence for each branch of the phylogeny is denoted by the size of the circles (larger circles have higher confidence). Abbreviated genus names are Microbacterium (Mic.), Rheinheimera (Rhe.), Achromobacter (Ach.), Undibacterium (Und.) and Porphyrobacter (Por.). Strain codes beginning with ' $N$ ' were isolated and characterized in the present study, all others were characterized using the same method in an earlier study (Godwin and Cotner, 2015b). The heatmap and phylogenetic tree were created using the Interactive Tree of Life (http://itol.embl.de). The color reproduction of this figure is available at the ISMEJ journal online. 
Table 1 Tests of phylogenetic signal for biomass stoichiometric ratios (log-transformed), stoichiometric flexibility, elemental quotas (logtransformed) and SRP

\begin{tabular}{|c|c|c|c|c|c|}
\hline Parameter & $\mathrm{n}$ & Lambda & $\mathrm{P}$-value & K & P-value \\
\hline$\mu_{\max }$ & 136 & 0.652 & $<1 \times 10^{-10}$ & 0.036 & 0.001 \\
\hline $\mathrm{C}: \mathrm{P}_{\text {biomass }}$ at $\mathrm{C}: \mathrm{P}_{\text {supply }}=100: 1$ & 135 & 0.535 & $<1 \times 10^{-10}$ & 0.024 & 0.007 \\
\hline $\mathrm{C}: \mathrm{P}_{\text {biomass }}$ at $\mathrm{C}: \mathrm{P}_{\text {supply }}=10000: 1$ & 128 & 0.182 & 0.042 & 0.022 & 0.033 \\
\hline $\mathrm{N}: \mathrm{P}_{\text {biomass }}$ at $\mathrm{C}: \mathrm{P}_{\text {supply }}=100: 1$ & 134 & 0.493 & $<1 \times 10^{-8}$ & 0.024 & 0.014 \\
\hline $\mathrm{N}: \mathrm{P}_{\text {biomass }}$ at $\mathrm{C}: \mathrm{P}_{\text {supply }}=10000: 1$ & 125 & 0.369 & 0.038 & 0.023 & 0.035 \\
\hline $\mathrm{C}: \mathrm{N}_{\text {biomass }}$ at $\mathrm{C}: \mathrm{P}_{\text {supply }}=100: 1$ & 134 & 0.248 & 0.009 & 0.022 & 0.017 \\
\hline $\mathrm{C}: \mathrm{N}_{\text {biomass }}$ at $\mathrm{C}: \mathrm{P}_{\text {supply }}=10000: 1$ & 125 & 0.031 & $>0.5$ & 0.017 & 0.366 \\
\hline $\mathrm{C}: \mathrm{P}_{\text {biomass }}$ flexibility & 127 & $<0.001$ & $>0.5$ & 0.028 & 0.039 \\
\hline $\mathrm{N}: \mathrm{P}_{\text {biomass }}$ flexibility & 124 & $<0.001$ & $>0.5$ & 0.021 & 0.136 \\
\hline C: $N_{\text {biomass }}$ flexibility & 124 & $<0.001$ & $>0.5$ & 0.017 & 0.407 \\
\hline $\mathrm{P}$ quota at $\mathrm{C}: \mathrm{P}_{\text {supply }}=100: 1$ & 100 & 0.440 & $<\mathbf{0 . 0 0 1}$ & 0.030 & 0.004 \\
\hline $\mathrm{P}$ quota at $\mathrm{C}: \mathrm{P}_{\text {supply }}=10000: 1$ & 93 & 0.285 & 0.014 & 0.032 & 0.003 \\
\hline C quota at $\mathrm{C}: \mathrm{P}_{\text {supply }}=100: 1$ & 99 & 0.328 & 0.011 & 0.029 & 0.005 \\
\hline $\mathrm{C}$ quota at $\mathrm{C}: \mathrm{P}_{\text {supply }}=10000: 1$ & 92 & $<0.001$ & $>0.5$ & 0.038 & $<0.001$ \\
\hline $\mathrm{N}$ quota at C: $\mathrm{P}_{\text {supply }}=100: 1$ & 98 & 0.366 & 0.001 & 0.030 & 0.005 \\
\hline $\mathrm{N}$ quota at $\mathrm{C}: \mathrm{P}_{\text {supply }}=10000: 1$ & 87 & 0.027 & $>0.5$ & 0.046 & $<0.001$ \\
\hline $\mathrm{SRP}$ at $\mathrm{C}: \mathrm{P}_{\text {supply }}=10000: 1$ & 104 & 0.100 & 0.058 & 0.015 & 0.56 \\
\hline
\end{tabular}

Abbreviation: SRP, soluble reactive phosphorus.

Compared with the phylogenetic signal expected from random trait evolution (Brownian motion), values of lambda $<1$ indicate low phylogenetic signal (or rapid evolution) and values $>1$ indicate strong signal. $P$-values for lambda are derived from a likelihood ratio test and $P$-values for $\mathrm{K}$ are based on randomization. $P$-values for significant effects $(P<0.05)$ are in bold.
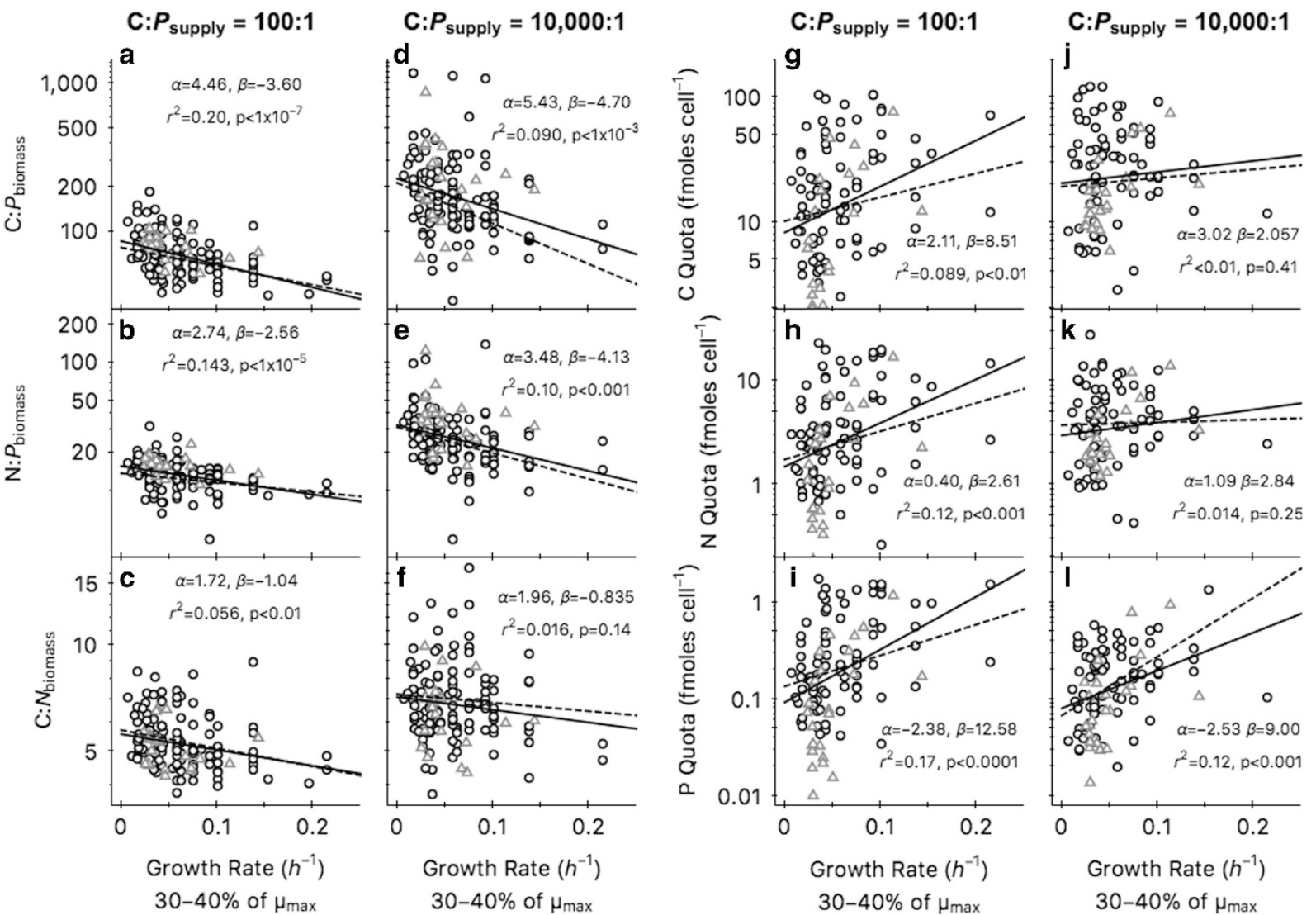

Figure 3 Dependence of biomass stoichiometry (a-f) and cell quotas ( $\mathbf{g}-\mathbf{l})$ on the growth rate of each strain. Circles denote isolates characterized in the present study and triangles denote isolates from Godwin and Cotner characterized using the same methods (Godwin and Cotner, 2015b). Solid lines are ordinary linear regressions and dashed lines are linear regressions accounting for phylogeny. Regression coefficients are based on regression for the equation $\log (y)=\alpha+\beta \mu$. Regression statistics for the phylogenetic regressions are displayed in Supplementary Table 3. Note that each strain was cultured at one dilution rate, equal to $30-40 \%$ of their $\mu_{\max }$. 
this relationship was weaker. Stoichiometric flexibility for $\mathrm{C}: \mathrm{P}, \mathrm{N}: \mathrm{P}$ and $\mathrm{C}: \mathrm{N}$ did not show any significant relationship with growth rate in the chemostats $\left(P>0.05, r^{2}<0.03\right)$ and including phylogeny did not improve the fit of these relationships. For a subset of isolates, we measured stoichiometry in batch cultures growing exponentially near $\mu_{\max }$ at $\mathrm{C}: \mathrm{P}_{\text {supply }}$ of $100: 1$. In batch cultures growing near their $\mu_{\max }$, strains with higher $\mu_{\max }$ had lower $C$ : $\mathrm{P}_{\text {biomass, }}, \mathrm{N}: \mathrm{P}_{\text {biomass }}$ and $\mathrm{C}: \mathrm{N}_{\text {biomass }}$ (Supplementary Figure S2). In these strains, the data from the batch cultures did not differ significantly from the chemostat cultures at C:P supply of 100:1 ( $\mu_{\max }$ by culture type interaction $P>0.05$ ).

Figures 3g-l show that at a C:P $\mathrm{P}_{\text {supply }}$ of 100:1, elemental quotas of $\mathrm{C}, \mathrm{N}$ and $\mathrm{P}$ increased significantly with $\mu_{\max }$, although these relationships were weak ( $r^{2}$ of $0.07-0.15$ ). At C:P $P_{\text {supply }}$ of $10000: 1, C$ and $\mathrm{N}$ quotas showed no relationship with $\mu_{\max }$, but $\mathrm{P}$ quotas increased significantly with $\mu_{\max }$. The phylogenetic regressions of quotas versus $\mu_{\max }$ were insignificant except for $\mathrm{P}$ quotas at $\mathrm{C}: \mathrm{P}_{\text {supply }}$ of $10000: 1$. The regressions of log-transformed cell quotas indicated that $\mathrm{C}$ and $\mathrm{N}$ were correlated, with a slope not significantly different from 1 (Figure 4). The regressions that were performed agnostic to phylogeny showed that the slope of $\mathrm{P}$ versus $\mathrm{C}$ quota was significantly greater than 1 at $\mathrm{C}: \mathrm{P}_{\text {supply }}$ of 100:1 and the slope for $\mathrm{P}$ versus $\mathrm{N}$ quotas was significantly greater than 1 at both C:P $\mathrm{P}_{\text {supply }}$ of 100:1 and 10 000:1. This result was not supported by the phylogenetic regressions, in which the slopes of $P$ versus $C$ and $P$ versus $\mathrm{N}$ did not differ from 1. For each of the element quotas, there was a positive but weak $\left(r^{2}<0.2\right)$ correlation between the quota at $\mathrm{C}: \mathrm{P}_{\text {supply }}$ of 100:1 and 10 000:1.

Only a subset of the traits exhibited significant differences between oligotrophic and eutrophic lakes (Figure 5). The strains from eutrophic lakes had significantly higher $\mu_{\max }$, lower $\mathrm{N}: \mathrm{P}_{\text {biomass }}$ at $\mathrm{C}: \mathrm{P}_{\text {supply }}$ of $10000: 1$, and lower $\mathrm{N}: \mathrm{P}_{\text {biomass }}$ flexibility than strains from oligotrophic lakes. However, when controlling for phylogenetic dependence (phylogenetic ANOVA), the ecosystem trophic state did not have a significant effect on any of these traits $(P>0.05$, Supplementary Table 4). Compared with strains isolated with acetate, those originating from glucose media had lower $\mathrm{N}$ and $\mathrm{P}$ quotas at $\mathrm{C}: \mathrm{P}_{\text {supply }}$ of $10000: 1$ and greater $C: \mathrm{N}_{\text {biomass }}$ flexibility and these effects were evident in both the phylogenetically agnostic tests of the median and the phylogenetic ANOVA. The C:P of the medium used for isolation did not have any significant effects on the trait values of the resulting isolates.

\section{Discussion}

We sought to identify the factors that best predict the elemental content and stoichiometric plasticity of aquatic bacteria. Despite finding a wide range of physiologies among our isolates, stoichiometry and elemental quotas showed little dependence on the source environment, phylogeny, or $\mu_{\max }$. These observations indicate that there is no single factor that explains interspecific patterns in elemental composition and stoichiometric flexibility, but rather, these characteristics are likely the result of multiple factors (discussed in Merchant and Helmann, 2012). In the following sections, we discuss the patterns in elemental composition and stoichiometric flexibility among isolates and the implications of this 'stoichiometric diversity'.

\section{Patterns in stoichiometry among strains}

We found that bacteria exhibited a broad range of biomass stoichiometry at C:P $\mathrm{P}_{\text {supply }}$ of 100:1. This variability means that even in the absence of strong resource imbalance or differences in relative growth rate, bacterial assemblages are composed of populations with different biomass stoichiometry. This result is similar to previous studies showing variation in biomass stoichiometry among strains under near-balanced resource stoichiometry (Mouginot et al., 2014; Zimmerman et al., 2014). Although the biomass stoichiometry at $\mathrm{C}: \mathrm{P}_{\text {supply }}$ of 100:1 ranged from $26: 4: 1$ to $188: 4: 1$, the quotas of $C, N$ and $P$ each varied by nearly two orders of magnitude under the same conditions, which shows that $\mathrm{C}, \mathrm{N}$ and $\mathrm{P}$ are tightly coupled under balanced resource availability (Figure 4).

In contrast, $\mathrm{C}, \mathrm{N}$ and $\mathrm{P}$ were more weakly coupled when the resource stoichiometry was unbalanced. Under P limitation, the median C:N:P of the isolates was 164:25:1, reflecting lower P quotas coupled with higher $\mathrm{C}$ and $\mathrm{N}$ quotas compared with C:P $\mathrm{P}_{\text {supply }}$ of 100:1. Increasing $C$ quotas under $P$ limitation has been observed previously and could be attributed to accumulation of C-rich compounds in intracellular pools (Thingstad et al., 2005). However, because N storage is apparently less common than storage of C or P (Sterner and Elser, 2002), the simultaneous increase in $\mathrm{N}$ quotas suggests that the cells are increasing in size or simply accumulating macromolecules with low $\mathrm{P}$ content such as protein. As C quotas increased proportionally more than $\mathrm{N}$ quotas under $\mathrm{P}$ limitation (Figure 4), strains exhibited greater flexibility in $\mathrm{C}: \mathrm{P}_{\text {biomass }}$ than in $\mathrm{N}: \mathrm{P}_{\text {biomass. }}$ This pattern suggests that, under $\mathrm{P}$ limitation, bacterial biomass can 'absorb' more of the surplus $C$ from the environment than N. Cells that increase their C content in response to $\mathrm{P}$ limitation often achieve this through an increase in cell size (Thingstad et al., 2005; Godwin and Cotner, 2015b). Lacking detailed measurements of cell size in our experiment, we analyzed forward scatter data from flow cytometry (Supplementary Figure S3). Forward scatter, which is proportional to cell size, was positively correlated with $\mu_{\max }$, but there was no correlation between forward scatter and C:P $\mathrm{P}_{\text {biomass }}$ or flexibility. We did 

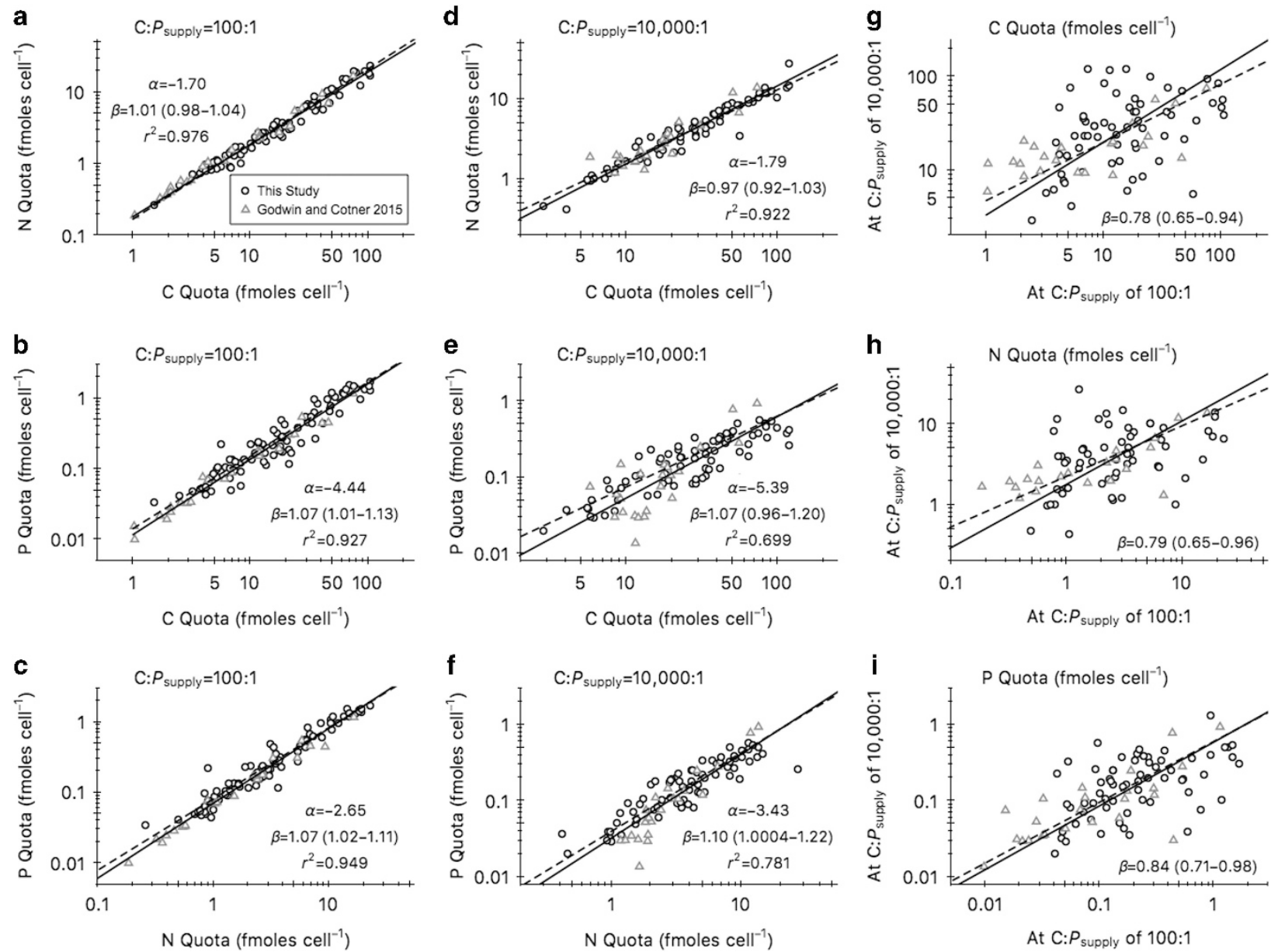

Figure 4 Standardized major axis regressions of cellular C, N and P quotas under $\mathrm{P}$ sufficiency (a-c) and P limitation (d-f). The right column ( $\mathbf{g}-\mathbf{i})$ shows the correspondence between the quota under P sufficiency and P limitation. Solid lines are unadjusted SMA regressions and dashed lines are phylogenetic RMA regressions. Regression coefficients are based on unadjusted SMA regression for the Equation $\log (y)=\alpha+\beta * \log (x)$. The confidence interval for $\mathbf{b}$ in each regression is displayed in parentheses. The phylogenetic RMA regression slopes were significantly different from 1 for $\mathbf{a}$ and $\mathbf{d}$.

find that C:P flexibility was correlated with the change in forward scatter between P sufficiency and P limitation: cells that increased their biomass C:P also increased their relative size $\left(r^{2}=0.1\right)$. This finding is consistent with previous work (Thingstad et al., 2005; Godwin and Cotner, 2015b), but the modest strength of the relationship means that morphological change is not the main driver of stoichiometric flexibility in our isolates.

We found a large gradient of stoichiometric flexibility among these strains as shown by the continuous distributions in Figure 1. Although some of the isolates had inflexible stoichiometry, most strains could at least double their $\mathrm{C}: \mathrm{P}_{\text {biomass }}$ and $\mathrm{N}$ : $\mathrm{P}_{\text {biomass }}$ under $\mathrm{P}$ limitation. Although it is sometimes assumed that heterotrophic bacteria are stoichiometrically inflexible (that is, they are homeostatic), our study shows that heterotrophic bacteria exhibit as much flexibility in their C:N:P $\mathrm{P}_{\text {biomass }}$ as algae (Persson et al., 2010; Hillebrand et al., 2013). Importantly, the continuum of stoichiometric flexibility was gradual and did not contain distinct sub-populations that shared a similar level of stoichiometric flexibility. Therefore, no single strain can represent the stoichiometric diversity present within a natural community. Mechanistic or heuristic models that omit this stoichiometric diversity will not adequately predict the response of bacterial communities to resource imbalance, nor will they adequately represent the effects of bacteria on biogeochemical variables in aquatic ecosystems. Research on phytoplankton has begun to integrate stoichiometry and community ecology using trait-based ecology (Bonachela et al., 2016). A similar approach could be used for bacteria, but in both cases the lack of data on drivers of stoichiometric flexibility remains an obstacle.

\section{Phylogenetic patterns in stoichiometry}

Bacterial $\mu_{\max }$, biomass stoichiometry and elemental quotas showed modest phylogenetic signals (lambda values), but stoichiometric flexibility exhibited very low phylogenetic signal in those same strains. 

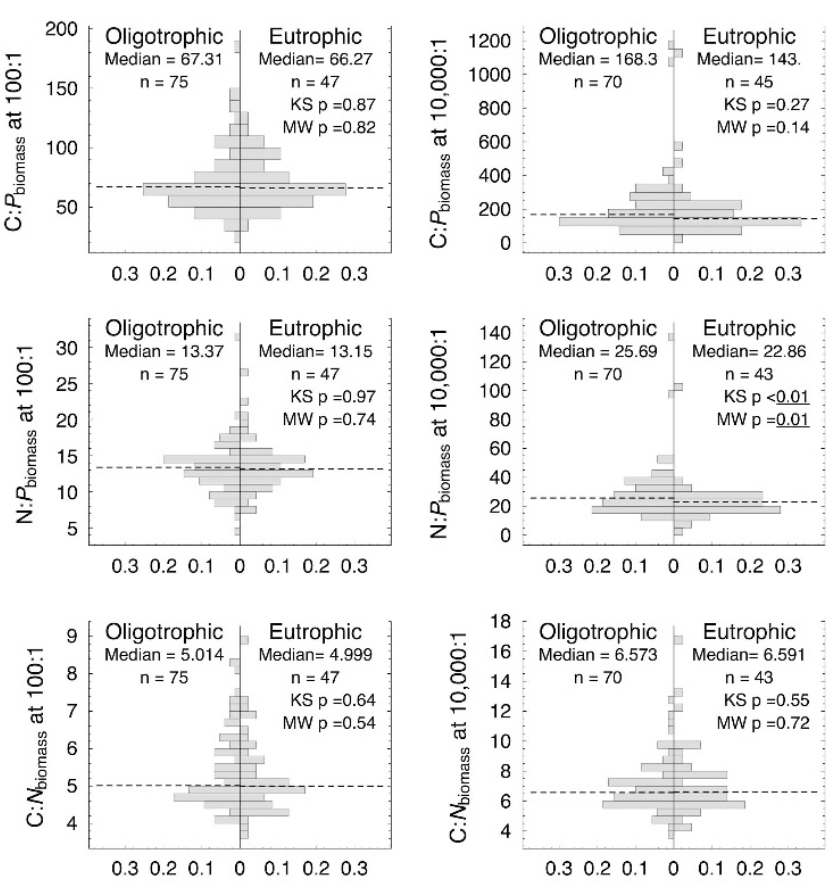

Proportion of Strains

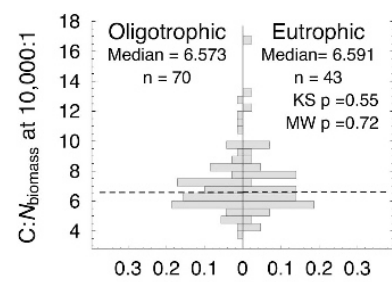

Proportion of Strains
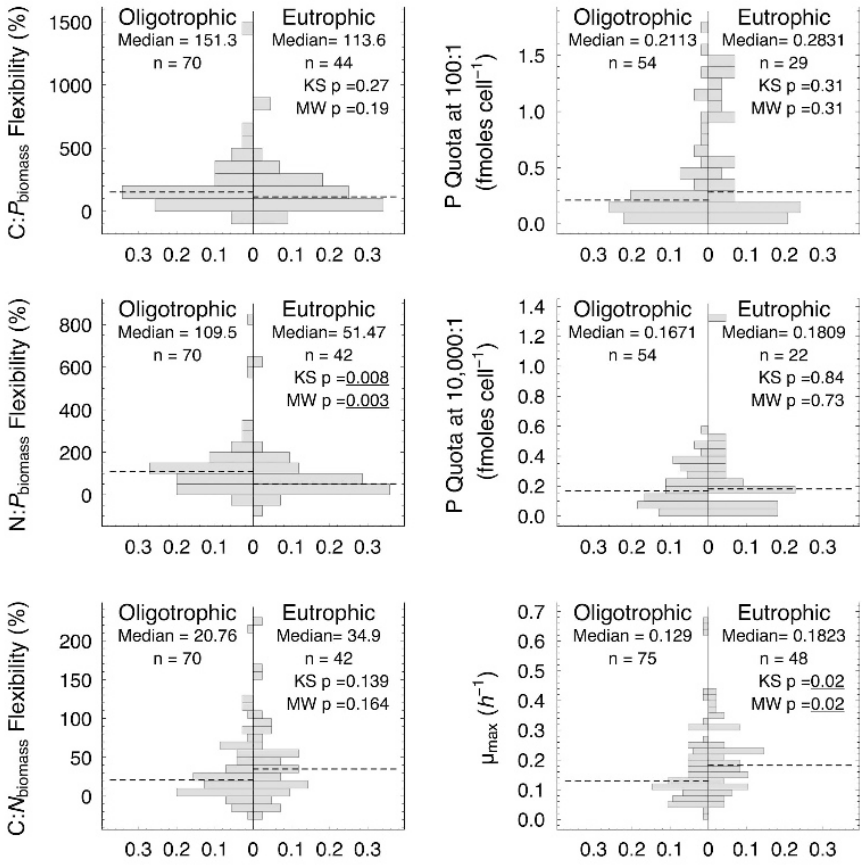

Proportion of Strains

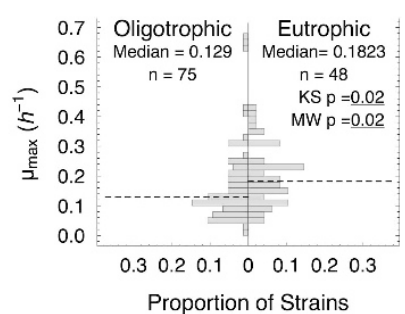

Figure 5 Paired histograms of biomass stoichiometry, flexibility, $\mu_{\max }$ and $\mathrm{P}$ quotas for isolates originating from oligotrophic and eutrophic lakes. In each histogram, the dashed line denotes the median value. Inset in each plot are: the total number of strains in each category (n), the $P$-value for the Kolmogorov-Smirnov test for similarity of distributions (KS), and the $P$-value for the Mann-Whitney test for equivalence of medians (MW). Results of phylogenetic ANOVA by trophic state are given in Supplementary Table 4.

Although there were some differences at the level of phyla (for example, the gamma-proteobacteria had higher $\mu_{\max }$ and lower biomass $\mathrm{C}: \mathrm{P}$ and $\mathrm{N}: \mathrm{P}$ than other groups), most clades showed substantial variation among their member strains. Other studies that have examined phylogenetic patterns in biomass stoichiometry produced similar results (Supplementary Table 5), although only for a single level of resource stoichiometry. Although specific traits involving $\mathrm{C}$ metabolism or physiological tolerance tend to show phylogenetic patterns (Martiny et al., 2015), the elemental content of a bacterium depends upon numerous pathways and processes, in context of the cell's environment and resources. As such, it would be surprising if stoichiometric flexibility showed a strong phylogenetic signal. This finding means that 16S-based phylogenetic affiliation would be inadequate to predict whether a strain has flexible stoichiometry. However, an important next step will be to identify the genes that are associated with flexible stoichiometry, which has already been explored in the zooplankter Daphnia (Jeyasingh et al., 2009).

Dependence of quotas and stoichiometry on $\mu_{\max }$ The GRH predicts that biomass $\mathrm{P}$ content is proportional to growth rate under $\mathrm{P}$ limitation, and although this relationship was significant among our strains, the predictive power was very weak $\left(r^{2}<0.16\right)$, regardless of whether we considered phylogenetic dependence or not. At a given $\mu_{\max }$, there was too much variability in the stoichiometric ratios among strains for the GRH to be a useful predictor of elemental content or stoichiometry. For instance, for strains with $\mu_{\max }$ between 0.1 and $0.2 \mathrm{~h}^{-1}$, each of the three element quotas varied by at least an order of magnitude among isolates. Although there is strong support for the GRH from comparisons among some groups of species (Elser et al., 2000), and for the effect of relative growth rate in a single species (Chrzanowski and Kyle, 1996; Makino et al., 2003), our study supports previous work showing that $\mu_{\max }$ and $\mathrm{P}$ content are weakly correlated among microbial taxa (Mouginot et al., 2014; Zimmerman et al., 2014).

Although the GRH was initially applied to the effect of relative growth rate on the $\mathrm{P}$ content of a single species (Elser et al., 2003), it is often extended to predict that biomass $\mathrm{C}: \mathrm{P}$ and $\mathrm{N}: \mathrm{P}$ are negatively correlated with growth rates among species (Hillebrand et al., 2013). We found that C:P, N:P and C:N ratios were negatively correlated with $\mu_{\max }$, both in continuous culture at 0.3-0.4 $\mu_{\max }$ and in batch culture at $\mu_{\max }$. Although the pattern in $\mathrm{C}: \mathrm{P}_{\text {biomass }}$ and $\mathrm{N}: \mathrm{P}_{\text {biomass }}$ is consistent with the GRH, there are few caveats worth noting. First, the correlation between stoichiometry and $\mu_{\max }$ was in many cases significant, but the predictive power was very weak $\left(r^{2}<0.1\right)$. Therefore, $\mu_{\max }$ is not a reliable predictor of $\mathrm{P}$ quota or stoichiometry among different strains of bacteria. Second, the negative correlation between $\mu_{\max }$ and $\mathrm{C}: \mathrm{N}_{\text {biomass }}$ is not predicted by the GRH and suggests that some of the pattern in 
$\mathrm{C}: \mathrm{P}_{\text {biomass }}$ and $\mathrm{N}: \mathrm{P}_{\text {biomass }}$ is attributable to changes in $\mathrm{C}$ and $\mathrm{N}$ content rather than $\mathrm{P}$. And last, the GRH originally applied only to P-limited growth (Elser et al., 2000), but we did not observe a stronger relationship under $\mathrm{P}$ limitation compared with $\mathrm{P}$ sufficiency. Together, these results show that the GRH is perhaps best suited to predicting within-strain physiological plasticity than among-strain patterns.

\section{Prevalence of stoichiometric physiologies across} trophic states

The results from our study offer mixed support for our hypothesis that isolates from eutrophic lakes would have higher $\mu_{\max }$, less flexible stoichiometry and larger element quotas than isolates from oligotrophic lakes. Isolates from eutrophic lakes did exhibit higher $\mu_{\max }$ than those from oligotrophic lakes (Figure 5), and because $\mu_{\max }$ showed stronger phylogenetic signal than the other parameters, this outcome suggests that the nutrient- and energy-rich conditions of eutrophic lakes contain proportionally more strains from phyla with higher $\mu_{\max }$, particularly the phyla gamma-proteobacteria and bacteroidetes. We did not detect a difference in C:P flexibility across trophic states, but N:P flexibility was significantly higher among isolates from oligotrophic lakes. This was not explained by a difference in flexibility of $\mathrm{N}$ or $\mathrm{P}$ quotas between the trophic states (t-test, all $P>0.5$ ). Following Jeyasingh et al. (2017), we compared the relative change in $\mathrm{N}$ quotas between P-sufficient and P-limiting conditions versus the change in $\mathrm{P}$ quotas (Supplementary Figure S4). Compared with strains from oligotrophic lakes, strains from eutrophic lakes were less likely to increase their $\mathrm{N}$ quota while simultaneously decreasing their $\mathrm{P}$ quota under $\mathrm{P}$ limitation. This finding supports our hypothesis that nutrient-poor environments can select for flexible stoichiometry.

We did not find any significant differences in elemental quotas among isolates from oligotrophic versus eutrophic environments. This result is surprising given the wide range of $\mathrm{C}, \mathrm{N}$ and $\mathrm{P}$ quotas we observed. One possible explanation for our finding is that the direct influence of $\mathrm{N}$ and $\mathrm{P}$ availability on the distribution of freshwater bacteria is weak. We suggest that future studies examining the ecological importance of elemental quotas in freshwater bacteria separate the direct effects of nutrient availability from indirect effects on primary producer biomass, organic $\mathrm{C}$ availability and organic $\mathrm{C}$ quality. In addition, studies will need to examine the ecological consequences of fixed versus flexible stoichiometry under non-equilibrium conditions (Lopez et al., 2016). We acknowledge that isolation and cultivation can exclude a large portion of the taxa present in natural communities (Colwell and Grimes, 2000). Several of these clades that we isolated are known to be abundant in intact communities (Newton et al., 2007; Livermore et al., 2014), so whether or not the strains described here are representative of the diversity found in lakes, our results show that all of those assemblages contain a wide range of stoichiometric physiologies.

\section{Conclusions}

From the experiments we describe here, it is apparent that stoichiometric flexibility is ubiquitously among isolates from lakes, and that the extent to which isolates exhibit flexibility is similar between trophic states. Moreover, the elemental content and stoichiometric flexibility of isolates are not adequately predicted from $\mu_{\max }$ or phylogenetic association. Although simple correlates of stoichiometric flexibility could allow us to infer the physiology of strains or assemblages, the results of this study do not mean that this problem is irreducibly complex. Instead, we suggest a model in which assemblages are composed of a continuum of phenotypes from homeostatic to highly flexible. The aggregate behavior of an assemblage is dependent upon the interaction of the stoichiometric flexibility of the component strains and community interactions such as competition and predation, leading to flexible stoichiometry of assemblages (Godwin and Cotner, 2014). Flexible biomass stoichiometry of assemblages reduces the imbalance between biomass stoichiometry and the supply of resources in the environment, so this physiology should be incorporated into models of biogeochemical cycling by bacteria.

\section{Conflict of Interest}

The authors declare no conflict of interest.

\section{Acknowledgements}

This work was supported by NSF-IOS award 1257571 to JBC. Andrea Little, Emily Whitaker, Chandra Dahlke, Maddy Jackson and Cole Spencer helped to run the experiment.

\section{References}

American Public Health Association. (1995). Standard Methods for the Examination of Water and Wastewater: Including Bottom Sediments and Sludges, 20th edn. American Public Health Association: New York.

Blomberg SP, Garland T, Ives AR. (2003). Testing for phylogenetic signal in comparative data: behavioral traits are more labile. Evolution 57: 717-745.

Bonachela JA, Klausmeier CA, Edwards KF, Litchman E, Levin SA. (2016). The role of phytoplankton diversity in the emergent oceanic stoichiometry. J Plankton Res 38: 1021-1035.

Chrzanowski TH, Kyle M. (1996). Ratios of carbon, nitrogen and phosphorus in pseudomonas fluorescens 
as a model for bacterial element ratios and nutrient regeneration. Aquat Microb Ecol 10: 115-122.

Colwell RR, Grimes DJ. (2000). Nonculturable Microorganisms in the Environment. ASM press: Washington, DC.

Davelaar D. (1993). Ecological significance of bacterial polyphosphate metabolism in sediments. Hydrobiologia 253: 179-192.

Droop MR. (1973). Nutrient limitation in osmotrophic protista. Am Zool 13: 209-214.

Elser JJ, Sterner RW, Gorokhova E, Fagan WF, Markow TA, Cotner JB et al. (2000). Biological stoichiometry from genes to ecosystems. Ecol Lett 3: 540-550.

Elser JJ, Acharya K, Kyle M, Cotner J, Makino W, Markow T et al. (2003). Growth rate-stoichiometry couplings in diverse biota. Ecol Lett 6: 936-943.

Freckleton RP, Harvey PH, Pagel M. (2002). Phylogenetic analysis and comparative data: a test and review of evidence. Am Nat 160: 712-726.

Galbraith ED, Martiny AC. (2015). A simple nutrientdependence mechanism for predicting the stoichiometry of marine ecosystems. Proc Natl Acad Sci USA 112: 8199-8204.

Garcia NS, Bonachela JA, Martiny AC. (2016). Interactions between growth-dependent changes in cell size, nutrient supply and cellular elemental stoichiometry of marine synechococcus. ISME J 10: 2715-2724.

Garland T, Dickerman AW, Janis CM, Jones JA. (1993). Phylogenetic analysis of covariance by computer simulation. Syst Biol 42: 265-292.

Ghosh S, LaPara TM. (2007). The effects of subtherapeutic antibiotic use in farm animals on the proliferation and persistence of antibiotic resistance among soil bacteria. ISME Jl 1: 191-203.

Godwin CM, Cotner JB. (2014). Carbon:phosphorus homeostasis of aquatic bacterial assemblages is mediated by shifts in assemblage composition. Aquat Microb Ecol 73: $245-258$.

Godwin CM, Cotner JB. (2015a). Aquatic heterotrophic bacteria have highly flexible phosphorus content and biomass stoichiometry. ISME J 9: 2324-2327.

Godwin CM, Cotner JB. (2015b). Stoichiometric flexibility in diverse aquatic heterotrophic bacteria is coupled to differences in cellular phosphorus quotas. Front Microbiol 6: 159.

Godwin CM, Whitaker EA, Cotner JB. (2017). Growth rate and resource imbalance interactively control biomass stoichiometry and elemental quotas of aquatic bacteria. Ecology 98: 820-829.

Goldman JC, McCarthy JJ, Peavey DG. (1979). Growth-rate influence on the chemical composition of phytoplankton in oceanic waters. Nature 279: 210-215.

Goldman JC, Caron DA, Dennett MR. (1987). Regulation of gross growth efficiency and ammonium regeneration in bacteria by substrate C: N ratio. Limnol Oceanogr 32: 1239-1252.

Hendrixson HA, Sterner RW, Kay AD. (2007). Elemental stoichiometry of freshwater fishes in relation to phylogeny, allometry and ecology. J Fish Biol 70: 121-140.

Hillebrand H, Steinert G, Boersma M, Malzahn A, Léo Meunier C, Plum C et al. (2013). Goldman revisited: faster growing phytoplankton has lower n:P and lower stoichiometric flexibility. Limnol Oceanogr 58: 2076-2088.

Jeyasingh PD, Weider LJ, Sterner RW. (2009). Geneticallybased trade-offs in response to stoichiometric food quality influence competition in a keystone aquatic herbivore. Ecol Lett 12: 1229-1237.
Jeyasingh PD, Goos JM, Thompson SK, Godwin CM, Cotner JB. (2017). Ecological stoichiometry beyond redfield: an ionomic perspective on elemental homeostasis. Front Microbiol 8: 722.

Lebaron P, Servais P, Agogue H, Courties C, Joux F. (2001). Does the high nucleic acid content of individual bacterial cells allow us to discriminate between active cells and inactive cells in aquatic systems? Appl Environ Microbiol 67: 1775-1782.

Livermore JA, Emrich SJ, Tan J, Jones SE. (2014). Freshwater bacterial lifestyles inferred from comparative genomics. Environ Microbiol 16: 746-758.

Lopez JS, Garcia NS, Talmy D, Martiny AC. (2016). Diel variability in the elemental composition of the marine cyanobacterium synechococcus. J Plankton Res 38: 1052-1061.

Makino W, Cotner JB, Sterner RW, Elser JJ. (2003). Are bacteria more like plants or animals? Growth rate and resource dependence of bacterial $\mathrm{C}: \mathrm{N}$ : P stoichiometry. Funct Ecol 17: 121-130.

Makino W, Cotner JB. (2004). Elemental stoichiometry of a heterotrophic bacterial community in a freshwater lake: implications for growth- and resourcedependent variations. Aquat Microb Ecol 34: 33-41.

Martiny AC, Ma L, Mouginot C, Chandler JW, Zinser ER. (2016). Interactions between thermal acclimation, growth rate, and phylogeny influence prochlorococcus elemental stoichiometry. PLoS One 11: e0168291.

Martiny JB, Jones SE, Lennon JT, Martiny AC. (2015). Microbiomes in light of traits: a phylogenetic perspective. Science 350: aac9323.

Merchant SS, Helmann JD. (2012). Elemental economy: microbial strategies for optimizing growth in the face of nutrient limitation. Adv Microb Physiol 60: 91.

Mouginot C, Kawamura R, Matulich KL, Berlemont R, Allison SD, Amend AS et al. (2014). Elemental stoichiometry of fungi and bacteria strains from grassland leaf litter. Soil Biol Biochem 76: 278-285.

Münkemüller T, Lavergne S, Bzeznik B, Dray S, Jombart T, Schiffers K et al. (2012). How to measure and test phylogenetic signal. Methods Ecol Evol 3: 743-756.

Narwani A, Alexandrou MA, Herrin J, Vouaux A, Zhou C, Oakley TH et al. (2015). Common ancestry is a poor predictor of competitive traits in freshwater green algae. PLoS One 10: e0137085.

Newton RJ, Jones SE, Helmus MR, McMahon KD. (2007). Phylogenetic ecology of the freshwater actinobacteria aci lineage. Appl Environ Microbiol 73: 7169-7176.

Nielsen SL, Enriquez S, Duarte CM, SandJensen K. (1996). Scaling maximum growth rates across photosynthetic organisms. Funct Ecol 10: 167-175.

Pagel M. (1999). Inferring the historical patterns of biological evolution. Nature 401: 877-884.

Persson J, Fink P, Goto A, Hood JM, Jonas J, Kato S. (2010). To be or not to be what you eat: regulation of stoichiometric homeostasis among autotrophs and heterotrophs. Oikos 119: 741-751.

Phillips KN, Godwin CM, Cotner JB. (2017). The effects of nutrient imbalances and temperature on the biomass stoichiometry of freshwater bacteria. Front Microbiol 8: 1692 .

Quigg A, Finkel ZV, Irwin AJ, Rosenthal Y, Ho T-Y, Reinfelder JR et al. (2003). The evolutionary inheritance of elemental stoichiometry in marine phytoplankton. Nature 425: 291-294.

Redfield AC. (1958). The biological control of chemical factors in the environment. Am Scientist 46: 205-221. 
Revell LJ. (2012). Phytools: an R package for phylogenetic comparative biology (and other things). Methods Ecol Evo 3: 217-223.

Rhee G-Y. (1973). A continuous culture study of phosphate uptake, growth rate and polyphosphate in scenedesmus sp. J Phycol 9: 95-506.

Rhee G-Y. (1978). Effects of N:P atomic ratios and nitrate limitation on algal growth, cell composition, and nitrate uptake. Limnol Oceanogr 23: 10-25.

Sardans J, Rivas-Ubach A, Peñuelas J. (2011). Factors affecting nutrient concentration and stoichiometry of forest trees in catalonia (ne spain). Forest Ecol Manage 262: 2024-2034.

Scott JT, Cotner JB, Lapara TM. (2012). Variable stoichiometry and homeostatic regulation of bacterial biomass elemental composition. Front Microbiol 3: 42.

Sterner RW, Elser JJ. (2002). Ecological Stoichiometry: The Biology of Elements from Molecules to the Biosphere. Princeton University Press: Princeton, NJ, USA.

Tamura K, Stecher G, Peterson D, Filipski A, Kumar S. (2013). Mega6: molecular evolutionary genetics analysis version 6.0. Mol Biol Evol 30: 2725-2729.
Tanner R. (2002)Cultivation of bacteria and fungiIn:Hurst C, Knudsen G, McInerney M, Stetzenbach L, Walter M (eds) Manual of Environmental Microbiology, 2nd edn2nd edn.ASM Press: Washington, DC.

Thingstad TF, Øvreas L, Egge JK, Løvdal T, Heldal M. (2005). Use of non-limiting substrates to increase size; a generic strategy to simultaneously optimize uptake and minimize predation in pelagic osmotrophs? Ecol Lett 8: 675-682.

Velji MI, Albright LJ. (1993). Improved sample preparation for enumeration of aggregated aquatic substrate bacteria. In: Kemp PF, Sherr BF, Sherr EB, Cole JJ (eds). Handbook of Methods in Aquatic Microbial ecology. Lewis Publishers: Boca Raton, pp 139-142.

Warton DI, Wright IJ, Falster DS, Westoby M. (2006). Bivariate line-fitting methods for allometry. Biol Rev 81: 259-291.

Zimmerman AE, Allison SD, Martiny AC. (2014). Phylogenetic constraints on elemental stoichiometry and resource allocation in heterotrophic marine bacteria. Environ Microbiol 16: 1398-1410.

Supplementary Information accompanies this paper on The ISME Journal website (http://www.nature.com/ismej) 